\title{
Agentes inteligentes na educação a distância: uso de sistemas tutores inteligentes como auxiliares no estabelecimento da comunicação dialógica
}

\author{
Valéria Cunha dos Santos ${ }^{1}$
}

\begin{abstract}
RESUMO
No contexto da Educação a Distância (EaD), a utilização de ferramentas como os Sistemas Tutores Inteligentes visa a contribuir para a facilitação do processo de ensino-aprendizagem. 0 intuito da aplicação desses sistemas é ampliar as possibilidades de contato entre aluno e professor/tutor, a partir de avaliações de dados quantitativos e de mensagens padronizadas que guiam a trajetória do estudante. Nesse contexto, o uso de inovações tecnológicas contribui para o avanço e o sucesso da EaD, favorecendo a aprendizagem e 0 trabalho de tutores e professores. Como no ensino a distância o processo educativo é realizado com a mediação de computadores e softwares, em muitos casos, o aluno aprende a utilizar o ambiente de aprendizagem no decorrer do curso. Por esse motivo, o sistema utilizado precisa ser autoexplicativo e apresentar uma linguagem clara e objetiva, própria para materiais didáticos, a fim de fornecer ao aluno o suporte necessário para que este se mova com autonomia em seu percurso formativo. As principais motivações para a adoção de Sistemas Tutores Inteligentes são a possibilidade de fornecer feedbacks do desempenho do estudante no ambiente virtual e a capacidade de ajuste do modelo de interface sensível às interações com o usuário, ambos fatores que são oportunizados por meio do estabelecimento da comunicação entre aluno/ambiente/professor-tutor. É pela recorrência da adoção de Sistemas Inteligentes em contextos educacionais que propomos, neste trabalho, uma reflexão, a partir da questão da afetividade, sobre 0 uso dessa ferramenta e a participação do tutor humano no processo de ensino-aprendizagem a distância.
\end{abstract}

PALAVRAS-CHAVE: Sistemas Tutores Inteligentes. Aprendizagem dialógica. Educação a Distância.

\begin{abstract}
With respect to Distance Learning, the use of tools such as Intelligent Tutoring Systems aims to contribute to the facilitation of the teaching-learning process. The purpose of the application of these systems is to increase the possibilities of contact between student and teacher / tutor, based on quantitative data evaluations and standardized messages that guide the student's learning journey. In this regard, the use of technological innovations contributes to the advancement and success of distance learning, improving the work of tutors and teachers. Since in this type of teaching the educational process is carried out through the mediation of computers and softwares, in many cases the student learns how to use the learning environment during the course. For this reason, the system used must be self-explanatory and present a clear and objective language, suitable for teaching materials in order to provide to the student the support needed during the course. The main motivations for the adoption of Intelligent Tutoring Systems are the possibility of providing feedbacks on student's performance in the virtual environment and the ability to adjust the interface model, both factors that are facilitated through the establishment of communication between student / environment / teacher-tutor.
\end{abstract}

KEYWORDS: Intelligent Tutoring Systems. Dialogic Learning. Distance Learning.

\footnotetext{
${ }^{1}$ Mestra em Linguística pela Universidade Federal de Santa Catarina (2015) e licenciada em Letras - Língua Portuguesa e Literaturas pela mesma universidade (2013). Atualmente, cursa doutorado em Teoria e Análise Linguística, linha de pesquisa Cognição e Uso, no Programa de Pós-Graduação em Linguística (UFSC). E-mail: csvaleriagı@gmail.com
} 


\section{Introdução}

A Educação a Distância (EaD) é uma modalidade de ensino que vem assumindo posição de destaque no cenário educacional. De acordo com Silva (2006), seu alcance e suas possibilidades de aplicação têm crescido de forma significativa pela ampliação do acesso à internet e pela integração das tecnologias da informação e da comunicação.

Conforme já apontava Mason (1998), a internet talvez seja a ferramenta educacional mais poderosa surgida nos últimos tempos. A utilização da internet com fins educacionais, além de propiciar o crescimento da EaD no âmbito acadêmico e coorporativo, tem impulsionado pesquisas na área da Ciência da Computação, principalmente associadas à tecnologia de agentes artificiais aplicada a Sistemas Tutores Inteligentes (STIs). Segundo Peters (2011), tais pesquisas se concentram em buscar alternativas para a criação de ambientes de ensino-aprendizagem inteligentes mais interativos e adaptativos ao perfil do aluno, uma vez que a Educação a Distância é caracterizada por atender a um público heterogêneo.

Os Sistemas Tutores Inteligentes, por meio da tecnologia de agentes, viabilizam a construção de ambientes de aprendizagem dinâmicos e adaptativos, tornando-os mais propícios ao desenvolvimento da autonomia do educando, principalmente por privilegiarem um modelo de ensino centrado no aluno, no qual este tem participação mais ativa no processo de aprendizagem. 0 uso dessa tecnologia visa aumentar o nível de interação entre os alunos em cursos a distância, à medida que implementa estratégias para supervisionar as suas ações e propor alternativas dinamicamente, de acordo com os princípios e a proposta pedagógica do curso em questão, em uma atuação que não sobreponha o trabalho do tutor - presencial ou a distância -, mas que vise agregar valor e qualidade às interações em um ambiente virtual de aprendizagem.

Entretanto, mesmo em uma sociedade em que os artefatos tecnológicos são amplamente utilizados e em que as relações pessoais são mediadas pela internet, ainda existem alguns estigmas que precisam ser superados quanto à utilização de agentes inteligentes na EaD. Um desses "tabus" é pensar que os alunos dessa modalidade de ensino possam vir a ser prejudicados por interagirem com uma máquina, e não com uma pessoa, ao realizarem um curso sob a mediação de Agentes Inteligentes. 
Considerando o cenário descrito, propomos aqui uma breve reflexão sobre o uso de sistemas de Agentes Inteligentes e o papel desempenhado por eles na educação. Para abordarmos questões relacionadas ao uso de Sistemas Tutores Inteligentes $e$ às possibilidades e limitações do uso dessa tecnologia para o ensino, trazemos, a seguir, uma breve explicação sobre STIs. Em seguida, discutimos sobre como o uso desses sistemas pode afetar os sujeitos - tutores, professores e alunos - envolvidos no processo de ensinoaprendizagem, no contexto da Educação a Distância. Por fim, traçamos algumas considerações finais.

\section{Sistemas Tutores Inteligentes}

Criados no fim da década de 1970, ganhando popularidade a partir dos anos 1990, Sistemas Tutores Inteligentes (STI) são softwares utilizados em cursos a distância que fornecem instruções e feedback aos alunos ao mesmo tempo em que uma tarefa é executada por eles. Assim, com o uso dos STIs é possível "aprender fazendo": o aluno aprende novos conteúdos durante a execução de uma atividade, monitorada pelo sistema, simulando a atuação de um tutor humano. Como aponta Viccari (1990), ao interagir com 0 aluno, os STIs modificam suas bases de conhecimento, ou seja, aprendem. Na interação, os Sistemas percebem as intervenções do aluno e podem adaptar as estratégias de ensino de acordo com o desenrolar do diálogo entre humano e máquina.

Uma das principais funções de um STI se refere à composição de interações educacionais de forma dinâmica. Nesse sentido, para ser inteligente, um STI precisa ser flexível, ter a capacidade de aprender com o ambiente e atualizar o seu conhecimento. E, além de ser utilizado para abordar algum conhecimento específico, o tutor inteligente deve inferir sobre como gerenciar o processo de ensino-aprendizagem durante a interação com 0 aluno. É por propiciarem um maior nível de interação entre o estudante e o sistema que os STIs têm se mostrado eficientes para a melhoria do desempenho e da motivação dos alunos (COSTA, 1999), pois se ajustam à realidade de aprendizagem na qual estão inseridos.

A arquitetura básica dos STIs possui quatro módulos: o do estudante, o do especialista, o módulo pedagógico e o da interface. 0 módulo do especialista possui as informações a respeito do conhecimento do conteúdo a ser ensinado. 0 módulo do 
estudante armazena as informações acerca da compreensão do aluno sobre o domínio de conhecimento em questão. 0 módulo pedagógico contém as regras para a tomada de decisão que permitem determinar o quanto o aluno está aprendendo. Já o módulo da interface apresenta ao usuário o ambiente de aprendizagem desenvolvido pelo especialista.

Essa arquitetura, baseada em agentes, substitui os módulos da arquitetura tradicional por uma sociedade de agentes que trabalha de forma cooperativa, compondo um Sistema Multiagentes (SMA). Nesse sistema, os agentes artificiais são "entidades de software que realizam algum conjunto de operações em benefício do usuário ou de outro programa, utilizando certo grau de independência ou de autonomia; e ao fazê-lo, empregam algum conhecimento ou representação dos objetivos ou preferências do usuário" (FLEISCHHAUER, 1996). Em resumo, os agentes artificiais de um STI interagem entre si e estabelecem relações de cooperação com o objetivo de promover a aprendizagem do aluno.

Esses Sistemas de Tutores Inteligentes são multiagentes, pois possuem diferentes componentes envolvidos no processo de ensino mediado por um sistema informatizado, a partir de diálogos, negociações e coordenação da transferência de informações, apresentando um comportamento determinado por um processo de raciocínio baseado na representação de suas atitudes (DIAS, 2008, p. 111). Conforme destacam Dorça e colegas (2002),

\begin{abstract}
as pesquisas em sistemas multiagentes enfatizam a inteligência coletiva, onde se busca a modelagem de sistemas através de um conjunto de agentes providos de uma série de habilidades cognitivas. Uma destas habilidades pode ser a habilidade para trabalhar com os seus pares. Um agente raciocina sobre 0 ambiente, sobre os outros agentes e decide racionalmente quais objetivos devem perseguir e quais ações devem tomar, agindo em cooperação com a sociedade (DORÇA et al., 2002, p.2).
\end{abstract}

A definição de uma modelagem com tais características garante não apenas que 0 sistema funcione, como também que o próprio sistema se autoavalie e resolva uma série de problemas que podem vir a surgir. Mais que isso, em um modelo baseado em teorias comportamentalistas de aprendizagem, um STI pode elaborar e propor avaliações aleatórias, com base no Modelo do Aluno, por meio da seleção de questões objetivas armazenadas em um banco de dados, com o objetivo de verificar o desempenho do aluno em determinados tópicos do conteúdo e, se necessário, indicar conteúdos que devem ser revisados ou aprofundados, etc. 
Ressaltamos, com Silva (2006), algumas especificidades dos STIs que podem contribuir para o processo de ensino-aprendizagem. Uma delas é a capacidade que esses sistemas têm de implementar estratégias pedagógicas necessárias para prover suporte a alunos em diferentes fases da aprendizagem. Isso ocorre porque os STIs consideram o aprender como um processo individualizado, pois levam em consideração que o conhecimento prévio do aluno e o seu estilo de aprendizagem influenciam na construção de novos conhecimentos. Nesse sentido, carregam instruções que são disponibilizadas de acordo com a demanda, possibilitando ao aluno aprender quando necessitar ou estiver interessado.

Sobre as possibilidades de aplicação dos STIs na EaD, Silva (2006) destaca desde ações operacionais simples até a adoção de estratégias pedagógicas, previamente definidas e desenhadas de acordo com a concepção do curso e o modelo de EaD adotado. Por exemplo, um STI pode incorporar recursos para identificar os tópicos visitados com maior frequência pelo aluno, com o objetivo de propor materiais complementares sobre o tema, enviando ao tutor um e-mail automático com tal solicitação e disponibilizando ao aluno materiais didáticos armazenados em uma base de dados previamente organizada, por meio de um serviço de busca.

Além disso, os sistemas inteligentes podem incorporar agentes de frequência, que monitoram os acessos dos alunos em cursos a distância e podem emitir sons ou exibir mensagens de orientação e/ou alerta, ou até mesmo imagens que representem o nível de satisfação do tutor com a frequência do aluno no curso. Gauthier \& Vavassori (1998), por exemplo, propõem um modelo que incorpora um agente de frequência representando ícones, que pode assumir diferentes expressões faciais. Segundo os autores, o agente de frequência passa para o aluno a impressão de que está sob a supervisão constante do tutor, o que pode propiciar maior segurança ao aluno e melhorar a sua assiduidade.

Os STI, aplicados a EaD, podem ainda incluir a tecnologia de agentes para análise de discussões síncronas e assíncronas realizadas em ambiente virtual. Jaques et al. (2000) propõem a arquitetura de um agente para realizar a análise quantitativa e qualitativa das trocas colaborativas que ocorrem entre alunos e tutores durante uma interação síncrona, com vistas a auxiliar o tutor em sua atuação como mediador, sobretudo em situações que envolvem um grande número de participantes e participações intensas. 
No entanto, cabe destacar que essas e outras possibilidades de aplicação de agentes artificiais no âmbito da Educação a Distância encontram-se em fase inicial, havendo ainda aspectos a serem aperfeiçoados e soluções a serem encontradas. Ainda que esse avanço no campo do ensino a distância seja promissor, tanto no que se refere ao ensino quanto à pesquisa para desenvolvimento dos próprios softwares, existem possibilidades e limitações que devem ser explorados no uso de STI.

Alguns dos problemas associados aos STIs estão relacionados ao alto custo financeiro e ao elevado tempo de desenvolvimento que demandam (HALL; WOOD, 1990; BECK et al., 1998). Na tentativa de reduzir custos, têm sido empregados conceitos da Engenharia de Software, como reutilização e modularidade, cujo foco consiste em desenvolver STI de forma incremental, permitindo uma evolução contínua e baseada em uma metodologia própria. No que se refere ao conhecimento do aluno, os STIs apresentam limitações para representar com precisão seus perfis e estágios de aprendizagem, para analisar seu raciocínio e para identificar a origem de possíveis conflitos entre o aluno e 0 sistema (HALL; WOOD, 1990). Quanto ao conhecimento pedagógico, muitos STIS implementam uma única estratégia pedagógica, o que se deve ao fato de as pesquisas nessa área terem se concentrado nos problemas de representação do conhecimento e diagnósticos e não nos processos pedagógicos envolvidos no ato de ensinar.

Sobre essa questão, Silva (2006) chama atenção para a dificuldade no desenvolvimento de Modelos do Aluno ao longo da evolução dos STIs, reflexo da restrição dos canais de comunicação via computador em comparação às possibilidades de comunicação entre um professor e um aluno. Nesse sentido, os STIs ainda apresentam desvantagens em comparação ao tutor humano, que possui capacidade de observação sensitiva, faz inferências sobre o comportamento do aluno e suas características, utilizando esses resultados para fazer 0 ajuste em suas estratégias de ensino. Outra limitação dos Sistemas, no âmbito da representação do conhecimento, é em relação à percepção e análise da motivação e do estado emocional do estudante. Isso faz com que possamos afirmar que os STIs evoluíram na representação de aspectos mensuráveis e previsíveis, como é o caso de certos avanços cognitivos do aluno, mas não na representação de estados emocionais e em outros fatores que nem sempre são passíveis de codificação. 


\section{Afetividade no processo de aprendizagem na EaD}

Ainda hoje, mesmo com uma grande quantidade de cursos a distância de qualidade certificada, comprovadamente eficazes, há um contraponto que é levantado muitas vezes ao se tratar do ensino a distância: o presencial. A modalidade presencial de ensino é mais tradicional, mais difundida e foi vivenciada pela maioria das pessoas escolarizadas, e talvez por isso existam crenças equivocadas sobre o sucesso da EaD. É importante pensarmos o porquê de a modalidade presencial ser vista como modelo e a não presencial como uma alternativa a um padrão, mas devemos, antes, questionar: o que caracteriza uma aula presencial e uma a distância?

Apesar de a aprendizagem e o incentivo à reflexão e à pesquisa serem objetivos em comum a ambas as modalidades, as metodologias adotadas por cada uma delas são distintas. A configuração mais comum de uma aula presencial é a de um professor, à frente da sala, para vários alunos. Já na educação a distância não há a necessidade de uma sala reservada para que todos possam se encontrar, os encontros são online em muitos casos. Enquanto o caderno e o quadro negro (ou o tablet e a lousa digital) estão muito mais presentes na educação presencial, na EaD o computador é o principal instrumento utilizado pelos participantes. Alguns aspectos nas aulas presenciais não se apresentam nas aulas da educação a distância e algumas diferenças entre essas modalidades de ensino estão na linguagem e nas tecnologias utilizadas, nas estratégias docentes de motivação, na interatividade e na relação com o conhecimento. Entretanto, mesmo diferentes, as modalidades podem funcionar juntas, complementarmente, como nos cursos semipresenciais, em que são somadas as características de cada metodologia formando uma nova, específica para certas finalidades.

Existem diferenças entre o ensino a distância e o presencial, pois são maneiras distintas de ensinar e aprender, cada uma com seus propósitos e públicos específicos. Ao tomar o ensino presencial como modelo a seguir, por ser o mais tradicional, as diferenças presentes na EaD podem ser vistas como prejuízos, ainda que equivocadamente, tão somente por receio no uso de inovações.

Um dos mitos relacionados ao ensino a distância é o de que os alunos são prejudicados, já que não há o contato "olho no olho" entre eles e o professor, e que erros na 
execução de tarefas não são corrigidos adequadamente uma vez que não há ninguém supervisionando essas atividades. Se trata de um mito porque, mesmo não havendo contato presencial entre todos os sujeitos envolvidos num curso EaD, existem encontros online, por meio de chats ou videoconferências, que garantem ao aluno a presença real de alguém do outro lado da tela. Além disso, a participação em fóruns e os feedbacks por parte dos professores tornam visíveis a supervisão das atividades e o acompanhamento ao longo do curso.

Do mesmo modo que no ensino presencial, é preciso que o professor se mostre presente e engajado ao objetivo dos alunos, e que os alunos aceitem os métodos e tarefas propostos pelo professor. Essa sintonia é acertada com diálogo e acordo, em qualquer que seja a modalidade de ensino aplicada. Especificamente na EaD, esse diálogo ocorre em ambientes virtuais, em sua maioria por depoimentos escritos, não necessariamente simultâneos, diferente da educação presencial, que utiliza mais a conversa oral, imediata. Ou seja, a interação entre os indivíduos não é garantida apenas pelo contato físico, mas pela comunicação, que ocorre nas duas modalidades.

Segundo Vygotsky (1993), a interação social é imprescindível para a aprendizagem e o desenvolvimento do ser humano, pois as pessoas adquirem novos saberes a partir de suas várias relações com o meio. Na concepção sócio-histórica de educação, a mediação é primordial na construção do conhecimento e ocorre, dentre outras formas, pela linguagem. É por meio do contato mediado pela linguagem que são constituídas as relações intersubjetivas, como a relação entre professor e aluno. A linguagem é o que intermedeia 0 contato, independente de proximidade geográfica, desde que sejam utilizados os devidos suportes. No contexto da EaD, o uso da escrita se sobressai enquanto estratégia comunicativa, pois as atividades são postadas em textos em sua maioria. Então, quanto mais esses textos favorecerem a comunicação clara entre os participantes do curso, mais efetiva será a interlocução.

É importante lembrar que, para que os indivíduos se comuniquem com êxito nos contextos a distância, o tempo de resposta não deve ser longo: seja a resposta de um questionamento ou o feedback de alguma atividade, o retorno do professor precisa ser feito o mais brevemente possível. Esse cuidado faz com que seja construído o reconhecimento de 
que há engajamento das partes na comunicação, essencial para o estabelecimento de uma relação dialógica.

Entretanto, cabe ressaltar que o professor ou o tutor podem ser sobrecarregados, dependendo do número de alunos sob sua orientação, o que pode acarretar no atraso das respostas ou em respostas excessivamente sucintas. É por isso que o desenvolvimento de mecanismos que auxiliam o trabalho do professor é tão importante. Os STIs, por exemplo, contribuem para que o avanço dos alunos seja mais rápido, propondo atividades com base nos resultados dos últimos acessos do aluno ao sistema, sem que seja preciso a mediação do tutor ou do professor para cada feedback. Com o auxílio desse tipo de tecnologia, não é preciso que todos os acessos sejam monitorados simultaneamente, pois o histórico de ações fica armazenado, e quando o professor/tutor acessar o sistema poderá ver o percurso do estudante e fazer sua avaliação.

A utilização de ferramentas, como os Sistemas Tutores Inteligentes, visa contribuir para a facilitação do processo de ensino-aprendizagem. 0 intuito não é criar uma barreira entre o aluno e o professor, deixando-os distantes e incomunicáveis, mas ampliar as possibilidades de contato. Ao sistema cabem as avaliações dos dados quantitativos e as mensagens padronizadas, enquanto que o professor fica encarregado da avaliação subjetiva, observando fatores que não podem ser calculados mecanicamente pelo computador.

Assim como vimos afirmando, o uso de inovações tecnológicas contribui para 0 avanço e o sucesso da EaD, favorecendo a aprendizagem e o trabalho de tutores e professores. Porém, pode não ser fácil lidar com tecnologias avançadas sem antes ter um treinamento. Em muitos casos de cursos a distância, o aluno "aprende fazendo", sem um preparo anterior, e, por isso, o sistema precisa ser bastante autoexplicativo além de utilizar uma linguagem clara e objetiva, própria para materiais didáticos.

É por isso que deve haver uma atenção voltada à interface, à "cara" que a estrutura dos conteúdos vai ter. A interface do sistema é o que aparece frente ao aluno no seu momento de estudo, e é no layout que estão dispostas as informações em links. Uma boa interface antecipa as ações do usuário e fornece um alto nível de interação: o usuário aprende a relação da interface junto com o conteúdo e, por isso, precisa interpretar constantemente as informações contidas no layout. Desse modo, o aluno precisa ser 
sensível para a compreensão das imagens em seus amplos significados, e para interpretá-las de acordo com o contexto em que estão inseridas.

No entanto, cabe ressaltar que não é o usuário quem deve adequar-se à interface, mas o contrário. Essa adequação será o primeiro termômetro motivacional na utilização do sistema. É o modelo de interface que emitirá a forma final da apresentação dos conteúdos, que funciona como a explicação do professor que guia o decorrer da aula. Caso o aluno não tenha facilidade para a navegação no sistema, pode se sentir desmotivado a seguir no curso.

Como já mencionamos, por mais que haja esforços a fim de tornar a relação entre usuários e interface dos STIs acessível, existem ainda limitações. Algumas delas estão associadas à falta de capacidade de hardware e de software em tratar aspectos relativos aos múltiplos sentidos do aluno, como olfato, tato e visão. O funcionamento dos STIs depende da reação do aluno, e mais ainda, que o aluno apresente essa reação de uma forma que o sistema possa ler. Atualmente, pesquisas vêm sendo desenvolvidas a fim de buscar maior aproximação entre as capacidades de um STI e de um tutor humano, para que o sistema considere aspectos emocionais e multissensoriais para planejar sua atuação junto ao aluno e selecionar estratégias de ensino, mas elas são muito recentes e, ainda assim, não substituem totalmente a ação humana.

Pelos motivos anteriormente elencados, para um melhor aproveitamento de seu potencial, as aplicações de STIs não devem visar à substituição do tutor humano por um tutor artificial, visto que as ações de ambos podem ocorrer no sentido de se complementarem. O STI deve ser adotado como uma ferramenta de apoio ao tutor e aos alunos, já que determinadas atividades de acompanhamento dos alunos durante o processo de ensino-aprendizagem e de construção do conhecimento só podem ser realizadas pelo tutor humano em interação com os estudantes.

Além disso, a prática tutorial precisa se ancorar na cooperação e na colaboração, seja ela feita por um tutor humano ou por um agente inteligente. Há algumas características esperadas do "tutor que se propõe a promover a mediação multimidiática do conhecimento a distância" que podemos listar, com base em Hack (2010), como características que também precisam ser levadas em conta na elaboração de um sistema inteligente. De acordo com o autor, o tutor deve: 
1. ser orientador do processo de ensino-aprendizagem e cooperador na construção do conhecimento;

2. explorar a comunicação educativa com os alunos, aumentando e melhorando a interatividade e comunicação com o estudante;

3. administrar o tempo e saber organizar as atividades para que as respostas aos estudantes sejam imediatas, com o intuito de promover constantemente o processo comunicacional dialógico;

4. ampliar as habilidades de comunicação interpessoal, articulando o diálogo entre alunos, professor e a equipe multidisciplinar;

5. trabalhar para que o ambiente onde o aluno se encontra seja motivador e acolhedor. No decorrer de um curso, o aluno pode se sentir desmotivado e quem vai incentiválo a fazer os exercícios e a acessar o ambiente virtual são os tutores humanos, que trabalham também offline. Mesmo que a vontade de permanecer no curso dependa do aluno, se não houver alguém que dê esse suporte, corre-se o risco que ele se perca no processo. Por isso, no ensino a distância, o tutor passa a ser visto como um conselheiro e também um orientador de aprendizagem do aluno. Rosatelli (2005 apud DIAS, 2008) desconstrói o professor-tutor como detentor do conhecimento e o transfere a responsabilidade de mediar, facilitar e estimular a construção dos conhecimentos, tarefas que, por enquanto, não cabem aos sistemas de inteligência artificial.

Os agentes inteligentes e tutores humanos podem ajudar o aluno a formular questionamentos e incentivá-lo a formar grupos de estudo, por exemplo. Porém, apenas o tutor percebe reações que ainda são imperceptíveis aos computadores mais simples, como os estados emocionais. 0 tutor humano pode ainda participar do processo de aprendizagem no estabelecimento de relacionamento interpessoal, ao aconselhar e ouvir as angústias dos alunos quando necessário, contribuindo para que os estudantes tenham condições de seguirem no processo de ensino-aprendizagem. Conforme afirma Hack (2010),

No que tange à dicotomia entre o cognitivo e o afetivo, Vygotsky (1993) aponta que a cognição possui estreita relação com a afetividade, ou seja, se separarmos o pensamento do afeto, fecharemos a possibilidade de explicar as causas do pensamento. Para o autor, quem separa o pensamento do afeto, nega a possibilidade de estudar a influência inversa do pensamento no plano afetivo, bem como impossibilita a análise que permitiria descobrir os motivos, as necessidades, os interesses, os impulsos $e$ as tendências que regem 0 movimento do pensamento (HACK, 2010, p. 08). 
Nesse viés, vale destacar que a EaD é uma modalidade de educação que exige maturidade do público-alvo e o desenvolvimento de algumas características como o autodidatismo, o comportamento autônomo e o trabalho colaborativo. Isso porque os ambientes virtuais de aprendizagem são “um espaço de ação gerenciado pelo próprio estudante" (BEZERRA; CARVALHO, 2011, p. 145) em grande parte do tempo. Para 0 desenvolvimento dessas características nos estudantes, deve-se

impulsionar a criação de ambientes motivadores e acolhedores, onde o equilibrio afetivo ajude $o$ aluno a vencer o medo de se comunicar ou apresentar suas ideias, expondo-as à interpretação e ao questionamento dos demais participantes do curso (HACK, 2010, p. 14).

Novamente vemos que a interação é essencial, seja entre humanos ou entre máquinas e humanos. Não há, portanto, porque desvincular o estabelecimento de relações do ensino a distância, simplesmente porque não faz sentido concebermos a educação como tarefa solitária. Ao tratarmos o desenvolvimento de sistemas e de tecnologias, considerando que a arquitetura de um STI deve ser formada pelos componentes dos modelos de domínio, de aluno, pedagógico e de interface, compreendemos que

a educação não pode se processar de forma fragmentada, mas coletivizada num grupo que se comunica e interage. Assim, cada qual, com sua função determinada, tem a possibilidade de, em diálogo com os demais componentes, oferecer crescimentos ao sistema (DIAS, 2008, p. 133).

Assim, mesmo com uma grande parcela de tecnologia, faz-se necessária a elaboração humana e o trabalho pedagógico para construir sistemas inteligentes capazes de efetivarem o processo de ensino-aprendizagem, de modo a auxiliar o trabalho de professores-tutores e alunos.

\section{Considerações finais}

O uso de Agentes Inteligentes na educação é uma forma de aprimorar e criar novas metodologias para o ensino. Entretanto, como discutimos aqui, a utilização dessa 
ferramenta, assim como de qualquer outra, inspira cuidados específicos e atenção por parte dos desenvolvedores e dos usuários.

Na aplicação de STIs na educação, vale lembrar que não é o usuário quem deve adequar-se à interface, mas o contrário. Caso o aluno não tenha facilidade para a navegação no sistema, surge a possibilidade do seu afastamento e da perda do vínculo que deve se estabelecer conforme o processo de ensino-aprendizagem se desenrola. Portanto, deve-se observar e cautelosamente trabalhar a escolha de uma linguagem adequada para comunicação de informações vindas tanto do sistema quanto do estudante.

Além de ser importante a observação do tipo de linguagem a ser utilizado, 0 estabelecimento da comunicação eficaz no contexto de uso de STIs depende muito da qualidade dos feedbacks enviados pelos alunos e professores/tutores. Essa estratégia é essencial para a avaliação dos alunos, do curso e do desempenho dos sistemas inteligentes. Isso porque o ambiente virtual é também espaço de múltiplas percepções e sensibilidades, que não são restritas à interação presencial, mas que estão presentes na linguagem. Daí a necessidade de a comunicação educacional manter-se fluida, constante e bidirecional, pois o estabelecimento do diálogo no contexto da EaD potencializa o uso das múltiplas tecnologias para a construção do conhecimento (HACK, 2013).

As estratégias para a Educação a Distância que foram e vêm sendo desenvolvidas avançaram tecnologicamente, inovando o modo de pensar sobre o processo de ensinoaprendizagem. Porém, vale lembrar que inovar não significa substituir, mas repensar o que está sendo feito, sem necessariamente abandonar métodos que são efetivos. Nesse sentido, não é conveniente excluir o papel desempenhado pelo professor na construção do conhecimento, mas é importante ressignificá-lo, principalmente diante do desenvolvimento de novas modalidades de ensino.

Na EaD, as turmas caracterizadamente são formadas por um grande número de alunos, o que acaba sobrecarregando tutores e professores, que dificilmente conseguem acompanhar o andamento dos estudantes no curso. Apesar de não haver barreiras físicas como as vivenciadas no ensino presencial, como limitação de espaço e de materiais, no ensino a distância pode haver uma limitação quanto ao estabelecimento da comunicação entre estudantes e professores/tutores, justamente pela grande quantidade de pessoas que podem estar envolvidas num mesmo ambiente virtual. 
Não havendo cuidado para a criação e manutenção de uma relação dialógica entre alunos e professores/tutores, os aspectos emocionais e relacionais vinculados à aprendizagem de conteúdos ficam fragilizados. É nesse espaço que os STIs atuam, com o uso de Agentes Inteligentes que auxiliam, dentre outras tarefas, no diálogo que perpassa a trajetória formativa em um ambiente educacional. Desse modo, a utilização desses sistemas nesse tipo de ambiente gera uma sensação de acompanhamento e amparo para 0 estudante desempenhar com autonomia seu papel de gerenciador do próprio percurso de aprendizagem.

\section{REFERÊNCIAS}

BARROS, M. G.; CARVALHO, A. B. G. As concepções de interatividade nos ambientes virtuais de aprendizagem. In: SOUSA, R., MIOTA, F., CARVALHO, A. (Org.). Tecnologias digitais na educação. Campina Grande: Eduepb, 2011. p. 125-140.

BECK, J.; STERN, M.; HAUGSJAA, E. Applications of Al in Education. The ACM's First Electronic Publication, 1998.

BEZERRA, M. A.; CARVALHO, A. B. G. Tutoria: concepções e práticas na educação a distância. In: SOUSA, R., MIOTA, F., CARVALHO, A. (Org.). Tecnologias digitais na educação. Campina Grande: Eduepb, 2011. p. 141-157.

COSTA, M. T. C. Uma Arquitetura Baseada em Agentes para Suporte ao Ensino à Distância. 1999. 100 f. Tese (Doutorado) - Programa de Pós-graduação em Engenharia de Produção, Universidade Federal de Santa Catarina, Florianópolis, 1999.

DIAS, D. S. F. Sistemas inteligentes na educação. 2008. Dissertação (Mestrado) - Programa de Pós-graduação em Educação, Universidade Federal da Paraíba, João Pessoa, 2008.

DORÇA, F. et al. Um sistema inteligente multiagente para educação à distância. Disponível em: <http://www.facom.ufu.br/ fabiano/publicacoes_arquivos/TecEADII_2002_2.pdf>. Acesso em: 16 set. 2013.

FILATRO, A. As teorias pedagógicas fundamentais em EAD. In: LITTO, Fredric M.; FORMIGA, Marcos. Educação a distância: o estado da arte. São Paulo: Pearson Education do Brasil, 2009. p. 96-104.

FLEISCHHAUER, L. I. A. O uso da tecnologia de agentes na Programação da Produção. Florianópolis. 1996. Dissertação (Mestrado) - Programa de Pós-Graduação em Engenharia de Produção, Universidade Federal de Santa Catarina, 1996. 
FRIGO, L. B.; POZZEBON, E. BITTENCOURT, G. O Papel do Agentes Inteligente em Sistemas Tutores Inteligentes. In: World Congress on Engineering and Technology Education, 2004, Guarujá / Santos. Engineering Education in the Changing Society, 2004.

GAUTHIER, F. A. O.; VAVASSORI, F. B. Proposta de Ferramentas e Agentes Inteligentes para um Ambiente de Ensino-Aprendizagem na Web. In: Simpósio Brasileiro de Informática na Educação (SBIE 98). Anais... Fortaleza, Ceará, 11, 1998.

HACK, J. R. Afetividade em processos comunicacionais de tutoria no ensino superior a distância. In: Foro Virtual de Virtual Educa Santo Domingo 2010. Santo Domingo: Virtual Educa, 2010. Disponível em: <http://www.hack.cce.prof.ufsc.br/wpcontent/uploads/2010/o1/VirtualEduca_2010_Hack.pdf>. Acesso em: 17 set. 2013.

Comunicação dialógica com múltiplas tecnologias na Educação a Distância. Aprendizagem. Pinhais: Editora Melo, ano 7, n.34, 2013, p. 20-21. Disponível em: <http://www.hack.cce.prof.ufsc.br/wpcontent/uploads/2013/06/Revista_aprendizagem_2013.pdf>. Acesso em: 17 set. 2013.

HALL, P.; WOOD, P. Intelligent Tutoring Systems: a review for beginners. Canadian Journal of Educational Communication, Canadá, v. 19, n. 2, 1990.

JAQ̨UES, P.; MORAES, M.; MORA, M. C. Uma Arquitetura de Agente para a Análise Qualitativa da Interação em Ambientes de Educação a Distância. In: XI SIMPÓSIO BRASILEIRO DE INFORMÁTICA NA EDUCAÇÃO. Anais... Maceió, 11, 2000.

MASON, R. Globalising education: trends and applications. London: Routledge, 1998.

MIL, D. Educação virtual e virtualidade digital: trabalho pedagógico na educação a distância na idade mídia. In: SOTO, U.; MAYRINK, M. F.; GREGOLIN, I. V. (Org.). Linguagem, educação e virtualidade. São Paulo: Cultura Acadêmica, 2009. p. 24-41.

PETERS, O. Didática do Ensino a Distância: experiências e estágio da discussão numa visão internacional. São Leopoldo: Unisinos, 2001.

RAMOS, R. C. G. Design de material didático on-line: reflexões. In: SOTO, U.; MAYRINK, M. F.; GREGOLIN, I. V. (Org.). Linguagem, educação e virtualidade. São Paulo: Cultura Acadêmica, 2009. p. 71-81.

SELF, J. Artificial Intelligence and human learning. London: Chapman Hall, 1988.

SILVA, A. P. C. Aplicações de Sistemas Tutores Inteligentes na Educação a Distância. Possibilidades e Limites. Relatório de Pesquisa. Brasília: UCB, 2006.

TROJAHN, C.; FROZZA, R.; DAHMER, A.; LUCIANO, G. Dóris - Um Agente de Acompanhamento Pedagógico em Sistemas Tutores Inteligentes. In: XII Simpósio Brasileiro de Informática na Educação. Anais do XII Simpósio Brasileiro de Informática na Educação. Vitoria: UFES, 2001. p. 437-444. 
VICCARI, R. M. Um Tutor Inteligente para a programação em Lógica -Idealização, Projeto e Desenvolvimento. Coimbra. Tese de Doutorado, Universidade de Coimbra, 1990.

VYGOTSKY, L. S. Pensamento e Linguagem. São Paulo: Martins Fontes, 1993.

Data de submissão: 10/09/2018. Data de aprovação: 05/11/2018. 